\title{
Simulation of the Flexural Response of Ultrahigh Performance Fiber-Reinforced Concrete with Lattice Fracture Model
}

\author{
Chunping Gu $\mathbb{D}^{1,2,3}$ Qiannan Wang, ${ }^{4}$ and Wei Sun ${ }^{4}$ \\ ${ }^{1}$ College of Civil Engineering and Architecture, Zhejiang University of Technology, Hangzhou 310014, China \\ ${ }^{2}$ Microlab, Faculty of Civil Engineering and Geosciences, Delft University of Technology, 2628 CN Delft, Netherlands \\ ${ }^{3}$ Key Laboratory of Civil Engineering Structures \& Disaster Prevention and Mitigation Technology of Zhejiang Province, \\ Zhejiang University of Technology, Hangzhou 310023, China \\ ${ }^{4}$ Jiangsu Key Laboratory of Construction Materials, School of Materials Science and Engineering, Southeast University, \\ Nanjing 211189, China
}

Correspondence should be addressed to Chunping Gu; guchunping@zjut.edu.cn

Received 1 February 2018; Revised 11 April 2018; Accepted 23 April 2018; Published 23 May 2018

Academic Editor: Peng Zhang

Copyright $(2018$ Chunping Gu et al. This is an open access article distributed under the Creative Commons Attribution License, which permits unrestricted use, distribution, and reproduction in any medium, provided the original work is properly cited.

The flexural response of ultrahigh performance fiber-reinforced concrete (UHPFRC) was simulated based on the lattice fracture model. Fiber was modelled as separated beam that was connected to the matrix with interface beams. The simulated results were compared with the experimental results. Deviations occurred at the late stage of the strain-softening period. But both the strainhardening behavior and multicracking phenomenon were observed in the simulation. The effects of fiber orientation and fiber content were studied with the lattice fracture model. The flexural strength and toughness of UHPFRC improved as the fibers were aligned distributed or the fiber content increased. The proposed model has the potential to help with the materials design of UHPFRC, and the limitations of the model were also discussed in the paper.

\section{Introduction}

Ultrahigh performance fiber-reinforced concrete (UHPFRC) was initially invented in 1980s in France $[1,2]$. In the revised recommendations on UHPFRC published by AFGC (Association Francaise de Génie Civil) [3], UHPFRCs are defined as materials with a cement matrix and a characteristic compressive strength of $150 \mathrm{MPa}-250 \mathrm{MPa}$. The most common methodology to prepare UHPFRC is cement + silica fume + very low water to binder $(\mathrm{w} / \mathrm{b})$ ratio + fine aggregate + superplasticizer + fiber [4]. Fibers are added to improve the ductility of UHPFRC. Thanks to its extremely excellent mechanical properties and durability, UHPFRC has been considered as the potential construction material for the next generation infrastructures [5]. The applications of UHPFRC are growing all over the world, especially in Europe, North America, Japan, Korea, and Australia. It has been widely applied for bridges, buildings, coastal structures, structural repairing, military structures, and so on [4]. However, the UHPFRC material design guides or codes are not fully developed right now, which inhibits the wider application of UHPFRC in infrastructure construction $[4,6]$.

With the increasing applications of UHPFRC, there is a clear need in developing material design methods for UHPFRC. Conventionally, UHPFRC is designed in the laboratory, with series of experimental tests. However, experiments will consume time, money, natural resources, energy, and so on. Therefore, numerical simulation has become popular to predict the properties of materials and could assist in the material design [7]. As for UHPFRC, its fracture process under the flexural load is very important when UHPFRC is applied for structures as large-span bridges and thin-wall shields. Many models have been proposed to simulate the fracture process of concrete under loads, such as discrete crack model $[8,9]$, smeared crack model $[10,11]$, damage model [12], and lattice fracture model [13]. Among them, the lattice fracture model is more suitable for the simulation of the flexural response of UHPFRC. 
The lattice fracture model was firstly developed by Schlangen and van Mier in 1990s [14]. Over the last few decades, it has been successfully used for the simulation of the fracture process in concrete. Based on the lattice fracture model, Arslan et al. simulated the strain-softening behavior of concrete under tension [15]; Vervuurt studied the interface fracture behavior of concrete [16]; Van Vliet investigated the size effect in tensile fracture of concrete and rock [17]; Man revealed the effect of aggregate shape on the compressive strength of concrete [18]; Caduff and van Mier analyzed the compressive fracture behavior of normal concrete, high-performance concrete, and foam concrete [19]; Grassl and Davies simulated the corrosion-induced cracking in reinforced concrete [20]; Montero and Schlangen modelled the fracture process of engineered cementitious composites (ECC) under uniaxial tension [21]; and Qian et al. simulated the fracture process of concrete considering the structural information of concrete at different scales [13]. Nevertheless, the application of the lattice fracture model for simulating the fracture process of fiber-reinforced concrete, especially UHPFRC, under the flexural load is rarely seen. In order to aid the material design, in this study, the flexural response of UHPFRC was simulated with the lattice fracture model; moreover, the effects of fiber content and orientation were studied and discussed.

\section{Description of the Lattice Fracture Model for UHPFRC}

The main idea of the lattice fracture model is to replace the composite by a network of beam elements [21]. The different phases are represented by beams with different materials properties. The procedures to perform lattice fracture simulation are shown in Figure 1.

The first step is to construct the lattice network. UHPFRC is considered to be composed of two phases, that is, the matrix and fibers [22]. Discrete fibers are embedded in the matrix. Correspondingly, in the lattice fracture model, fibers are implemented as discrete beam elements and are connected to the matrix elements with interface beams [21, 23], as shown in Figure 2. The network constructed by the matrix beams and nodes represents the matrix of UHPFRC. Since the matrix of UHPFRC is very homogenous, the lattice nodes are generated to at the center of the square grids so that a uniform network can be constructed. With a given volume fraction, fiber beams with a given diameter and length are generated and randomly distributed within the matrix. Along with the fiber beam, extra nodes were generated at the location where the fiber beam intersects the square grid. In order to represent the fibermatrix bond, interface beams were generated between the extra nodes and lattice nodes. More details on the lattice network construction for fiber-reinforced concrete can be found in [23].

After the lattice network construction, the mechanical properties of all the beams have to be assigned. According to the previous studies [21], the matrix and fiber beams are set to be brittle and will fail under tension at their

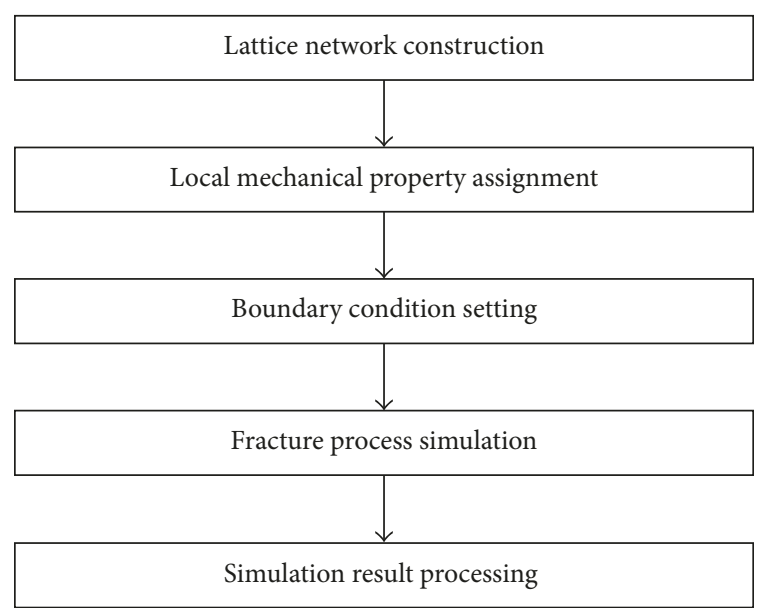

FIgURe 1: Procedures of lattice fracture simulation.

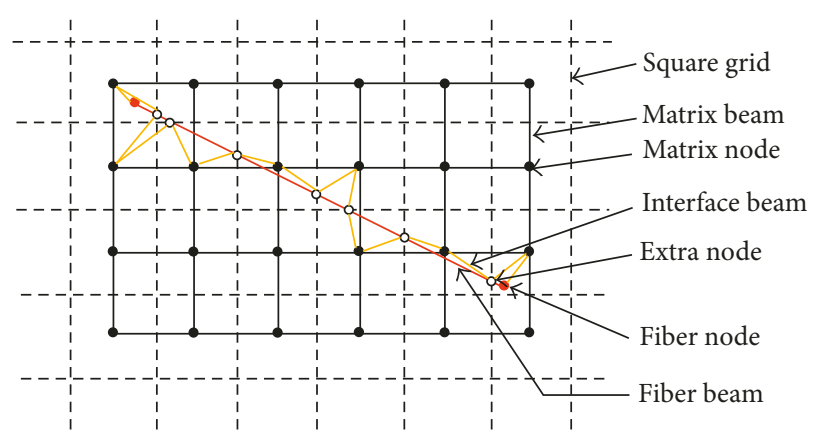

FIGURE 2: Schematic 2D representation of fiber-lattice construction.

corresponding tensile strength, and the interface beams are set to be ductile and can fail either in tension or compression. The material properties of the matrix and fiber beam can be obtained directly with experiments, and the properties of interface beam normally can be determined by fitting the experimental results of the single fiber pullout test $[21,24]$.

The lattice fracture model could simulate a series of mechanical tests in the lab, such as compressive test [6], tensile test [13], and flexural test. With different boundary condition settings on the lattice network, different mechanical tests can be simulated.

The fracture process simulation is described in detail in $[13,23,25]$. In summary, the fracture process is simulated step by step. At every step, a prescribed force or displacement is applied on the lattice network, and the stresses in the beams can be calculated. The beam with the highest stress/strength ratio is removed from the lattice network, representing the crack growth process. After the simulation, the stress-strain response diagram, the crack pattern, and the crack propagation process can be obtained.

\section{Simulation of Flexural Response of UHPFRC}

3.1. Proportion and Properties of UHPFRC. The flexural response of a typical UHPFRC with $2 \%$ steel fibers was simulated in the paper. The proportion of the UHPFRC is 
TABLE 1: Mixture proportion of UHPC $\left(\mathrm{kg} / \mathrm{m}^{3}\right)$.

\begin{tabular}{lcccccc}
\hline Cement & $\begin{array}{c}\text { Fly } \\
\text { ash }\end{array}$ & $\begin{array}{c}\text { Silica } \\
\text { fume }\end{array}$ & River sand & Superplasticizer & Water & $\begin{array}{c}\text { Steel } \\
\text { fiber }\end{array}$ \\
\hline 540 & 432 & 108 & 1296 & 37.8 & 172.8 & 160 \\
\hline
\end{tabular}

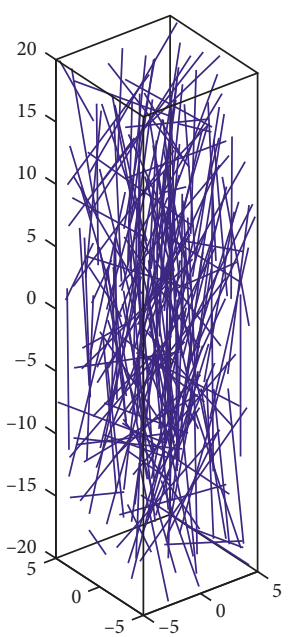

FIGURE 3: Fiber distribution in the UHPFRC prism.

shown in Table 1. Cement, fly ash, and silica fume were used as binders. River sand had a maximum particle size of $2.36 \mathrm{~mm}$. The superplasticizer was a type of liquid agent with a solid content of $28 \%$. The length, diameter, and tensile strength of steel fiber were $13 \mathrm{~mm}, 0.2 \mathrm{~mm}$, and $1800 \mathrm{MPa}$, respectively. The compressive strength and four-point flexural strength of UHPFRC after $90 \mathrm{~d}$ standard curing were $156.1 \mathrm{MPa}$ and $34.4 \mathrm{MPa}$, respectively.

3.2. Lattice Network Construction. Due to the limitation of computing efficiency, four-point flexural tests were simulated on a $10 \mathrm{~mm} \times 10 \mathrm{~mm} \times 40 \mathrm{~mm}$ prism. The fibers were considered to be randomly distributed in the prism. The fiber beams were generated following the method described in [21]. The simulated fiber distribution and corresponding lattice network are shown in Figures 3 and 4. The lattice network was constructed with the method mentioned in Section 2, and the mesh size was $1 \mathrm{~mm}$. The matrix beam and fiber beam are shown in blue and red, respectively, in Figure 4.

3.3. Local Mechanical Properties Assignment. From a general point of view, the flexural response of UHPFRC depends on the matrix parameters, fiber parameters, and fiber-matrix interface parameters. These parameters are also the inputs for the lattice fracture model. The input parameters for this study are shown in Table 2. The parameters for the matrix and steel fiber were obtained with experiments, and the parameters for the interface beams were fitted based on the experimental data from [26]. The matrix and fibers were considered as linear elastic (Figure 5(a)), while a seven segment ductile stress-strain response [21] (Figure 5(b)) was applied for interface elements in order to obtain more realistic results.

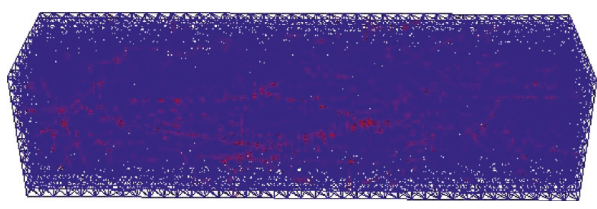

FIGURE 4: Lattice network of the UHPFRC prism.

TABLE 2: Input parameters for the lattice fracture model.

\begin{tabular}{lcccc}
\hline Element & $\begin{array}{c}\text { Young's } \\
\text { modulus } \\
(\mathrm{GPa})\end{array}$ & $\begin{array}{c}\text { Shear } \\
\text { modulus } \\
(\mathrm{GPa})\end{array}$ & $\begin{array}{c}\text { Tensile } \\
\text { strength } \\
(\mathrm{MPa})\end{array}$ & $\begin{array}{c}\text { Compressive } \\
\text { strength } \\
(\mathrm{MPa})\end{array}$ \\
\hline Matrix & 48 & 18 & 14 & - \\
Steel fiber & 200 & 80 & 1800 & - \\
& 16 & 8 & 500 & -500 \\
Interface & 8 & 4 & 500 & -500 \\
& 4 & 2 & 500 & -500 \\
& 1 & 1 & 500 & -500 \\
& 0.5 & 0.5 & 500 & -500 \\
& 0.25 & 0.125 & 500 & -500 \\
\end{tabular}

3.4. Boundary Condition Setting. The boundary condition was set following that happened in the experiments. A fourpoint bending test was set for the simulation, and an illustration is shown in Figure 6. In the lattice network, the arrow pointed nodes at the bottom were fixed, and a prescribed displacement was imposed on the arrow pointed nodes at the top for every step. The beams connected to these nodes were shown in red in Figure 6.

3.5. Simulation Results. Figure 7 shows the simulated loaddeformation curve of UHPFRC. It can be seen from Figure 7(a) that the lattice fracture model could give a reasonable flexural response of UHPFRC. Both the strain-hardening behavior and multiple cracking could be simulated. Nevertheless, it is unrealistic that the curve begins to go up when the deformation exceeds $2.5 \mathrm{~mm}$. At this stage, a large portion of the matrix beam have been broken, and the fiber beams and interface beams, which have higher mechanical properties, were connected to each other and might be bearing most of the loads. Hence, the load went up instead at the late stage. In Figure 7(b), the load-deformation curve before deformation reaches $0.2 \mathrm{~mm}$ is emphasized. Before step 100, UHPFRC showed an elastic behavior. When the stress in the matrix exceeded the matrix cracking strength, the first crack of the UHPC matrix occurred, and the crack began to propagate until fibers took over the load at step 500. Then, the second crack occurred at step 1000. The crack bridging effect of the fibers led to a strainhardening behavior of UHPFRC. During this process, the number of the cracks increased and individual cracks widened. At step 5000, UHPC began to fail. Fibers started to pull out from the matrix, and cracks began to localize.

Figure 8 shows the crack patterns in UHPFRC at different steps, and the broken beams are shown in blue. The white beams are broken beams at the end of the simulation. It can be seen from Figure 8 that, at step 100, UHPFRC started to crack. Only some beams at the bottom were 


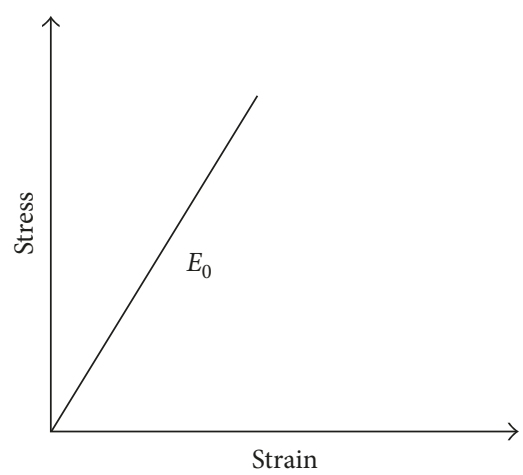

(a)

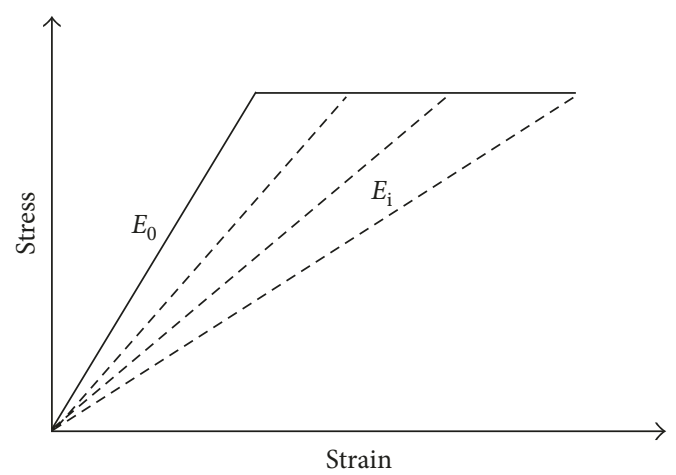

(b)

FIgUre 5: Mechanical properties of (a) matrix beam and fiber beam and (b) interface beam.

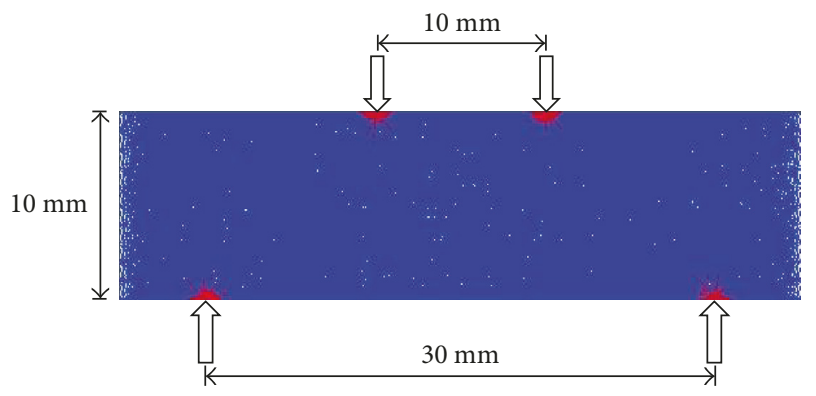

FIGURE 6: Four-point bending test setup for the UHPFRC prism.

broken. After that, the crack developed, and one straight crack formed at step 500. Then, this crack was bridged by fibers, and cracks at other location began to occur at step 1000. At step 5000, several cracks can be seen and UHPFRC started to fail.

3.6. Experimental Validation. In order verify the lattice fracture model, four-point bending tests were performed on UHPFRC specimens with a dimension of $40 \mathrm{~mm} \times$ $40 \mathrm{~mm} \times 160 \mathrm{~mm}$. The simulated and measured loaddeformation curves are compared in Figure 9. Although different specimen sizes were adopted in the simulation and experiments, it still can be seen that the load-deformation curves obtained by simulation and experiments were in a similar shape. For the simulated curve, the load increased very fast during the elastic and strain-hardening periods. The slow development of the load for the measured curve may be due to that the clamp and the specimen were not fully contacted at the beginning of the test. Flexural strengths of UHPFRC obtained from the simulation result and experimental result were 31.3 $\mathrm{MPa}$ and $34.1 \mathrm{MPa}$, respectively. The deviation is very small. The most obvious difference of the two curves occurred at the late stage of the strain-softening period. The load of the simulated curve increased at ending of the simulation, which was not in accordance with the reality. In the simulation, the interface beams were connected with the fiber beam and matrix nodes. There is also a chance that one matrix node was connected to two or more interface beams so that the interface beams and fiber beams may be connected to each other and hold the load together, when most of the matrix beams were broken. The input of the tensile strength for interface and fiber beams was much higher than the matrix beam; hence, the load increased at the late stage. One of the solutions to this problem is to reduce the grid size to avoid the direct connection between interface beams. But, under this circumstance, the computation will be more expensive.

In general, the presented lattice fracture model could reliably simulate the flexural response of UHPFRC before failure, and improvements have to be made to eliminate the deviation of the simulated load-deformation curve at the late stage.

\section{Effect of Fiber Orientation and Fiber Content on the Flexural Response of UHPFRC}

4.1. Fiber Orientation. It is well acknowledged that fiber orientation will definitely influence the mechanical properties of UHPFRC, especially the flexural and tensile strength. But, it is very difficult to control the fiber orientation in the experiments, while different fiber orientation could be implemented easily in the simulation.

In the lattice fracture model, theoretically, fiber can be distributed in any desired form. To demonstrate the potential application of the lattice fracture model, the effect of aligned and randomly distributed fibers on the flexural behavior of UHPFRC was studied. $2 \%$ steel fibers were added in UHPFRC, and the inputs and settings were the same as those in Section 3. Aligned distributed fibers are shown in Figure 10, and randomly distributed fibers are presented in Figure 3.

The simulated load-deformation curves of UHPFRC with aligned and randomly distributed fibers are shown in Figure 11. It can be seen that UHPFRC with aligned distributed fibers has a higher flexural strength than UHPFRC with randomly distributed fibers. Moreover, the area under the load-deformation curve of UHPFRC with aligned distributed fibers was also bigger than UHPFRC with randomly 


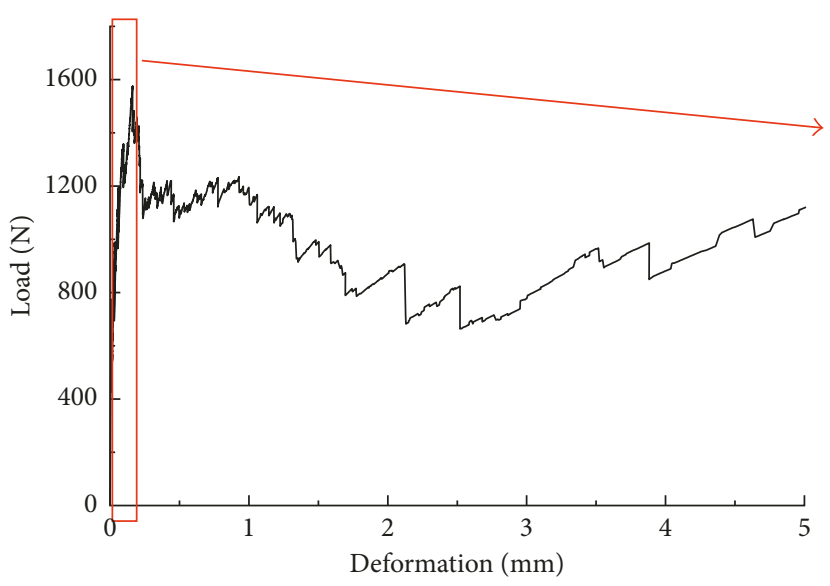

(a)

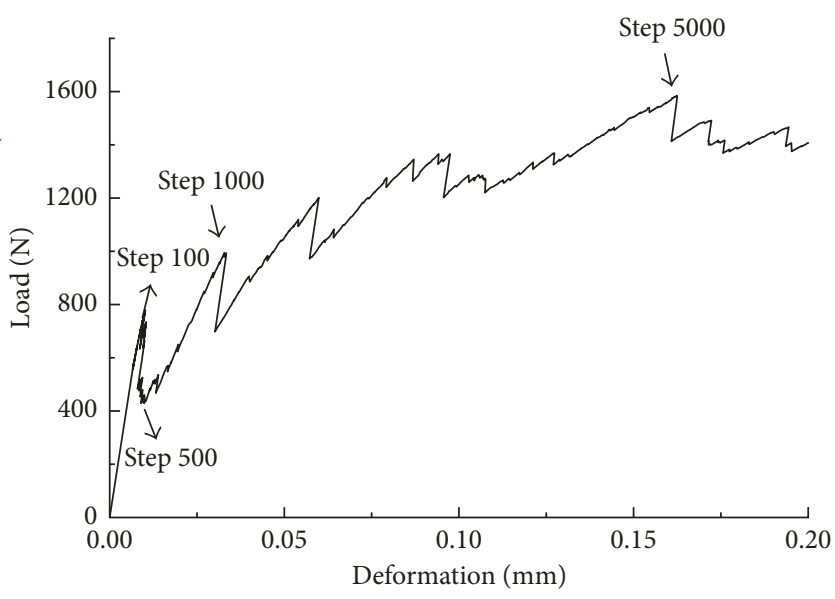

(b)

FiguRE 7: Simulated load-deformation curve of UHPFRC. (a) Full load-deformation curve. (b) Load-deformation curve before deformation reaches $0.2 \mathrm{~mm}$.

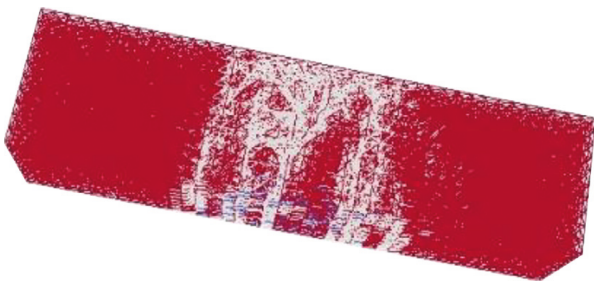

(a)

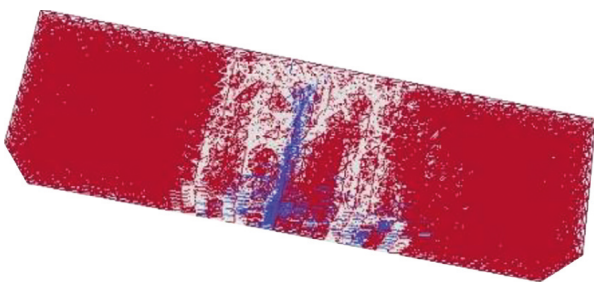

(c)

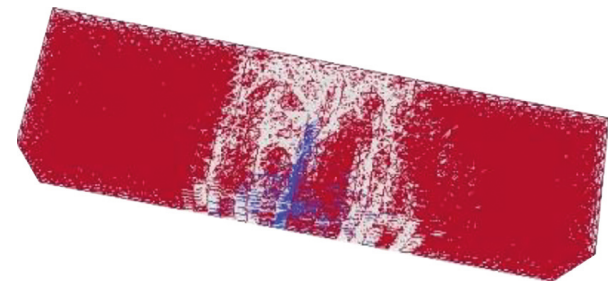

(b)

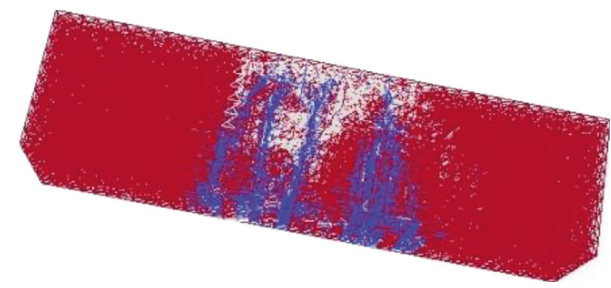

(d)

FIGURE 8: Crack patterns in UHPFRC at different steps: (a) 100, (b) 500, (c) 1000, and (d) 5000.

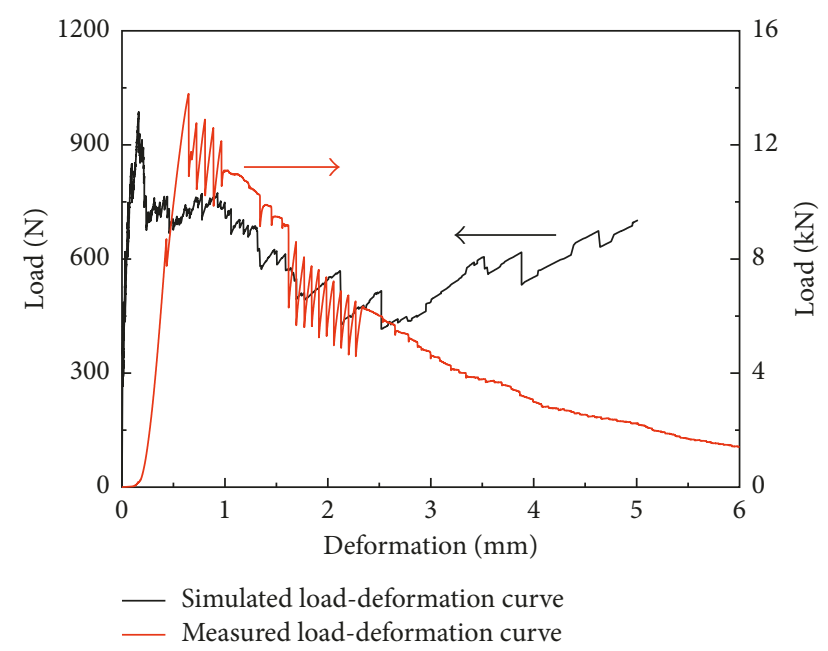

Figure 9: Load-deformation curves of UHPFRC obtained by simulation and experiment. distributed fibers, which implied UHPFRC with aligned distributed fibers had a higher toughness. In general, the aligned distributed fibers showed a better reinforcing and toughening effect on UHPFRC. The results are as expected.

Figure 12 shows the crack patterns of UHPFRC with aligned and randomly distributed fibers. Compared with UHPFRC with randomly distributed fibers, more cracks occurred in UHPFRC with aligned distributed fibers. The aligned distributed fibers did better in inhibiting the crack propagation than randomly distributed fibers. Hence, when preparing UHPFRC materials, a particular method could be applied to make fibers tend to be aligned distributed and be perpendicular to the crack, so that the flexural property of UHPFRC could be improved.

4.2. Fiber Content. It is anticipated that the increase of fiber content could improve the flexural strength and toughness of UHPFRC. This was also studied by comparing simulated 


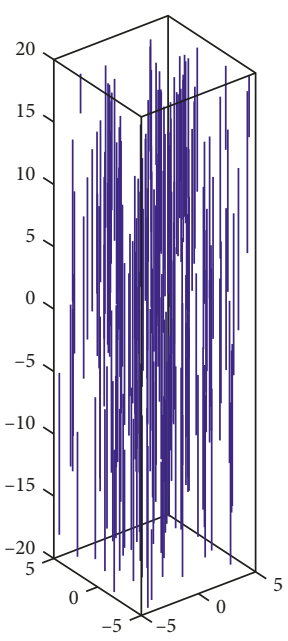

FIgURE 10: Aligned distributed fibers in the UHPFRC prism.

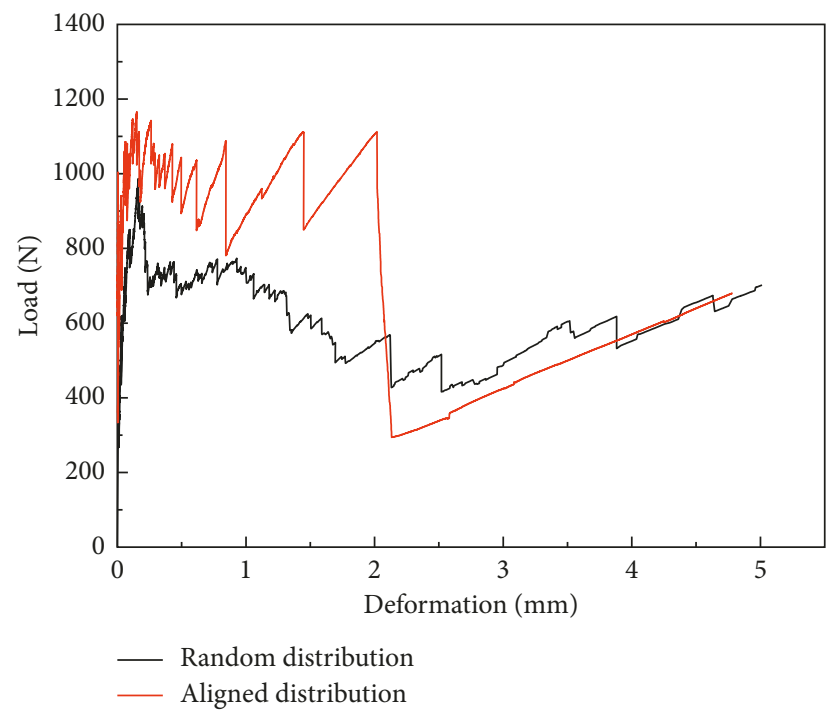

FIGURE 11: The simulated load-deformation curves for UHPFRC with different fiber orientation.

results of UHPFRC with different fiber contents. The other inputs and settings were also the same as those in Section 3. Four fiber volume fractions $\left(V_{\mathrm{f}}\right)$ were studied in this paper: $0 \%, 1 \%, 2 \%$, and $3 \%$. In Figure 13, the simulated loaddeformation curves of UHPFRC with different fiber contents are presented. It is observed that the flexural strength and toughness increased with the increase in fiber content. The results are also in accordance with the experimental results [26].

The crack patterns in UHPFRC with different fiber contents are shown in Figure 14. When fibers were not presented, the material was brittle and one single crack was developed (Figure 14(a)). As the fiber volume fraction increased, the main crack was bridged by fibers and other cracks were generated. With more fibers, more cracks were generated, and in other words, the multicracking phenomenon was more remarkable.

\section{Potential Applications and Limitations}

The lattice fracture model has been successfully used for simulating the uniaxial tensile behavior of pain concrete and fiber-reinforced concrete $[13,21,23]$. The results of this study showed that the lattice fracture model was also capable to simulate the flexural response of UHPFRC, which is one of typical fiber-reinforced concretes. Besides the fiber orientation and fiber content, the effect of different variables, for example, fiber strength, fiber stiffness, and fiber size, can be explored with the lattice fracture model as well. The effect of matrix composition on the flexural behavior of UHPFRC can also be addressed with the lattice fracture model at different length scales. The outcome of the simulation could contribute to the materials design of UHPFRC.

One drawback of the presented simulation is that the demand for computational time is very long, which caused that the sample size used in the simulations was much smaller than that in experiments. According to the simulated results, it is acceptable to simulate the flexural response of UHPFRC with a small size, but it is better to perform the simulation on UHPFRC with the same size as that used in experiments, if the computing efficiency could be improved. Hence, perfecting the algorithm of the lattice fracture model is necessary for the further improvements. Another solution of this problem is to develop an approach to determine the representative elementary volume (REV) size of UHPFRC for flexural response simulation. REV is the smallest volume, whose properties are representative of the whole material. Simulated flexural response of REV of UHPFRC could represent the actual flexural behavior of UHPFRC. Under this circumstance, the computational time could be reduced.

At present, the properties of interface beams can be determined only by fitting the experimental results. It may cause the problem that the fitted data could not be used for other UHPFRCs with confidence. Hence, a deeper understanding on the relationship between the matrix and interface properties is needed, and this can be obtained by simulations at a lower scale (nanoscale or microscale), or by series of experimental tests. More simulations or experiments should be performed to study the bond strength between the fibers and the matrix. It is important for the correct setting of the interface beam parameters in the lattice fracture model.

\section{Concluding Remarks}

In this paper, the flexural response of UHPFRC was simulated with the lattice fracture model. The properties of matrix, fiber, and interface were used as inputs. Both the strain-hardening behavior and multicracking phenomenon could be observed in the simulations. The simulated and tested load deflection curves were in a similar shape, except that deviations occurred at the late strain-softening period. The effects of fiber orientation and fiber content were studied with simulations. The flexural strength and toughness of UHPFRC were improved with aligned distributed fibers and with increased fiber contents.

In general, the lattice fracture model has proved to be an efficient numerical tool to simulate the flexural response of 


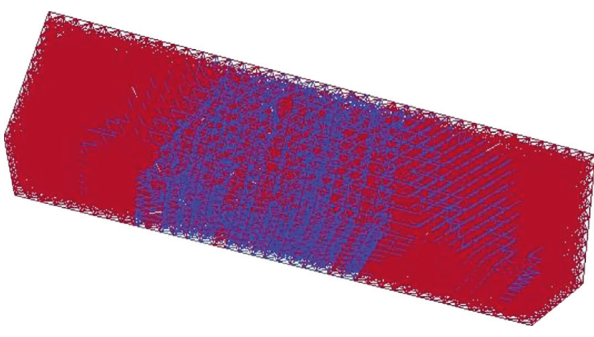

(a)

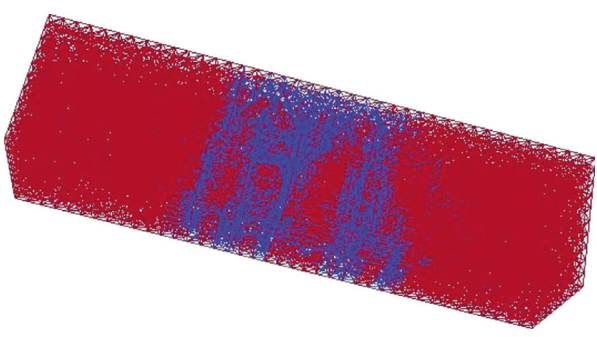

(b)

FIGURE 12: Crack patterns in UHPFRC with different fiber orientation. (a) Aligned distribution and (b) random distribution.

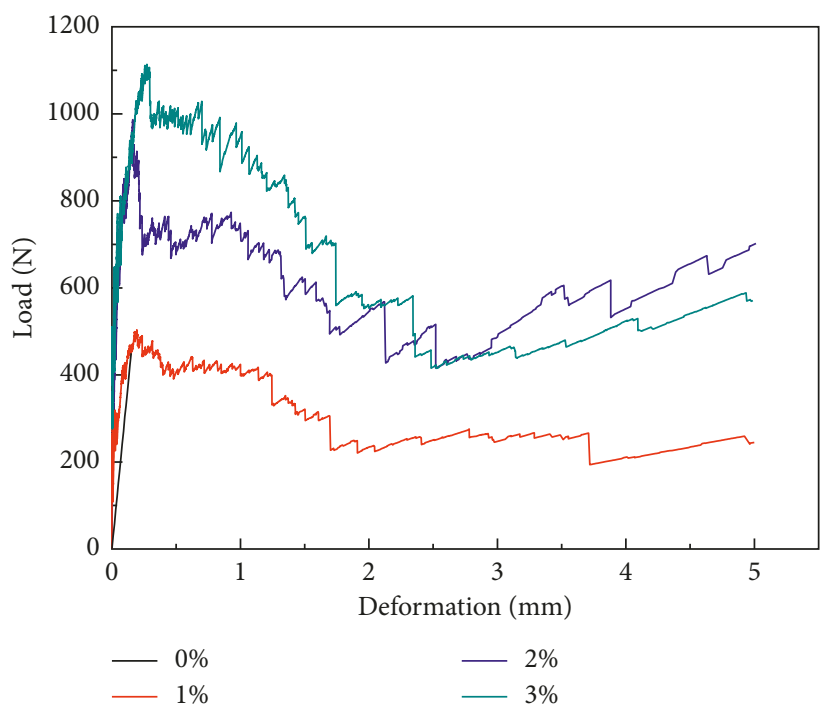

FIgURE 13: The simulated load-deformation curves for UHPFRC with different fiber contents.

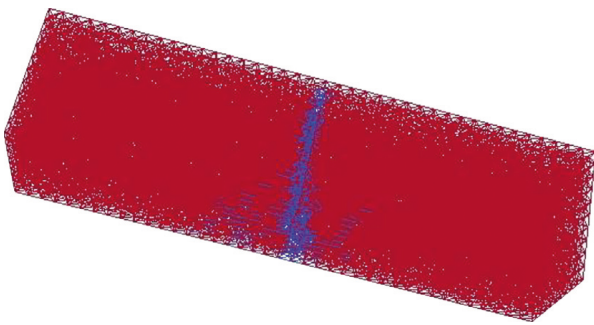

(a)

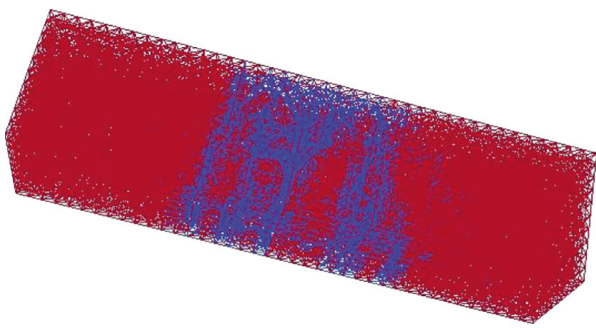

(c)

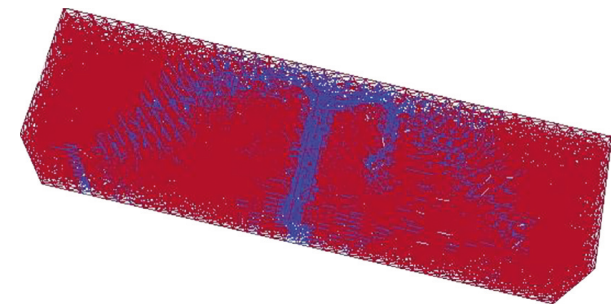

(b)

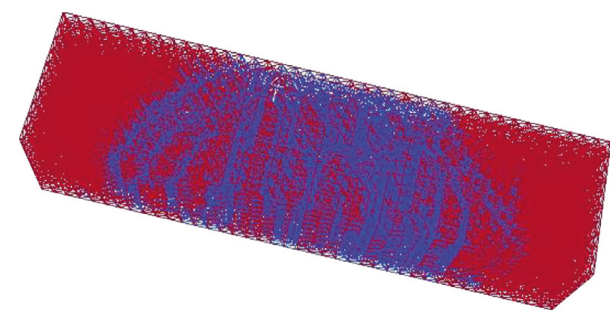

(d)

Figure 14: Crack patterns in UHPFRC with different fiber contents: (a) $V_{\mathrm{f}}=0 \%$, (b) $V_{\mathrm{f}}=1 \%$, (c) $V_{\mathrm{f}}=2 \%$, and (d) $V_{\mathrm{f}}=3 \%$. 
UHPFRC. Parameter studies will be conducted to reveal the effects of various parameters and testing configurations, and further studies could be focused on the determination of the interface beam properties of UHPFRC.

\section{Data Availability}

The authors declare that all the data supporting the findings of this study are available within the article.

\section{Conflicts of Interest}

The authors declare that they have no conflicts of interest.

\section{Acknowledgments}

Sincere acknowledgments are given to Dr. Guang Ye and Dr. Zhiwei Qian in the Delft University of Technology for their assistance in performing lattice fracture simulation. This work was supported by the National Natural Science Foundation of China (Grant no. 51708502), the China Postdoctoral Science Foundation Funded Project (Grant no. 2017M612028), and the Jiangsu Key Laboratory of Construction Materials Open Fund Program (Grant no. CM2018-12).

\section{References}

[1] P. Richard and M. Cheyrezy, "Composition of reactive powder concretes," Cement and Concrete Research, vol. 25, no. 7, pp. 1501-1511, 1995.

[2] M. Cheyrezy, V. Maret, and L. Frouin, "Microstructural analysis of RPC (reactive powder concrete)," Cement and Concrete Research, vol. 25, no. 7, pp. 1491-1500, 1995.

[3] AFGC, Ultra High Performance Fiber-Reinforced Concretes Recommandations-Revised Edition, AFGC, Paris, France, 2013.

[4] C. Gu, G. Ye, and W. Sun, "Ultrahigh performance concreteproperties, applications and perspectives," Science China Technological Science, vol. 58, no. 4, pp. 587-599, 2015.

[5] C. Gu, W. Sun, L. Guo, and Q. Wang, "Ultrahigh performance concrete: a potential material for sustainable marine construction in view of the service life," Applied Mechanics and Materials, vol. 438-439, pp. 108-112, 2013.

[6] R. El-Helou, E. Lale, G. Cusatis, and C. Moen, "Ultra-high performance concrete compression and fracture response parameters for lattice discrete particle model simulations," in Proceedings of the First International Interactive Symposium on UHPC, pp. 1-11, Des Moines, IA, USA, July 2016.

[7] F. Guala, Models, Simulations, and Experiments, Springer, New York, NY, USA, 2002.

[8] D. Ngo and A. Scordelis, "Finite element analysis of reinforced concrete beams," ACI Journal Proceedings, vol. 64, no. 3, pp. 152-163, 1967.

[9] R. de Borst, J. J. C. Remmers, A. Needleman, and M. A. Abellan, "Discretevs smeared crack models for concrete fracture: bridging the gap," International Journal for $\mathrm{Nu}$ merical and Analytical Methods in Geomechanics, vol. 28, no. 78, pp. 583-607, 2004.

[10] Y. R. Rashid, "Ultimate strength analysis of prestressed concrete pressure vessels," Nuclear Engineering and Design, vol. 7, no. 4, pp. 334-344, 1968.
[11] Z. P. Bazant and F. B. Lin, "Nonlocal smeared cracking model for concrete fracture," Journal of Structural Engineering, vol. 114, no. 11, pp. 2493-2510, 1998.

[12] J. L. Chaboche and P. M. Lesne, "A non-linear continuous fatigue damage model," Fatigue and Fracture of Engineering Materials and Structures, vol. 11, no. 1, pp. 1-17, 1988.

[13] Z. Qian, E. Schlangen, G. Ye, and K. van Breugel, "Modeling framework for fracture in multiscale cement-based material structures," Materials, vol. 10, no. 6, p. 587, 2017.

[14] E. Schlangen and J. G. M. van Mier, "Experimental and numerical analysis of micromechanisms of fracture of cement-based composites," Cement and Concrete Composites, vol. 14, no. 2, pp. 105-118, 1992.

[15] A. Arslan, R. Ince, and B. L. Karihaloo, "Improved lattice model for concrete fracture," Journal of Engineering $\mathrm{Me}$ chanics, vol. 128, no. 1, pp. 57-65, 2002.

[16] A. H. J. M. Vervuurt, Interface Fracture in Concrete, Ph.D. thesis, Delft University of Technology, Delft, Netherlands, 1997.

[17] M. R. A. Van Vliet, Size Effect in Tensile Fracture of Concrete and Rock, Ph.D. thesis, Delft University of Technology, Delft, Netherlands, 2000.

[18] H. K. Man, Analysis of 3D Scale and Size Effects in Numerical Concrete, Ph.D. thesis, Swiss Federal Institute of Technology, Zürich, Switzerland, 2010.

[19] D. Caduff and J. G. M. van Mier, "Analysis of compressive fracture of three different concretes by means of 3D-digital image correlation and vacuum impregnation," Cement and Concrete Composites, vol. 32, no. 4, pp. 281-290, 2010.

[20] P. Grassl and T. Davies, "Lattice modelling of corrosion induced cracking and bond in reinforced concrete," Cement and Concrete Composites, vol. 33, no. 9, pp. 918-924, 2011.

[21] F. Montero and E. Schlangen, "Modelling of fracture in fibrecement based materials," in Brittle Matrix Composites 10, pp. 51-60, Elsevier, London, UK, 2012.

[22] S. Zhao and W. Sun, "Nano-mechanical behavior of a green ultra-high performance concrete," Construction and Building Materials, vol. 63, pp. 150-160, 2014.

[23] E. Schlangen and Z. Qiang, "3D modeling of fracture in cement-based materials," Journal of Multiscale Modelling, vol. 1, no. 2, pp. 245-262, 2009.

[24] F. Montero, E. Schlangen, and F Medina, "A lattice-particle approach for the simulation of fracture processes in fibereinforced high-performance concrete," in Proceedings of 8 th International Conference on Fracture Mechanics of Concrete and Concrete Structures, J. van Mier, G. Ruiz, C. Andrade, R. Yu, and X. Zhang, Eds., pp. 1-8, Toledo, Spain, March 2013.

[25] Z. Qian, E. Schlangen, G. Ye, and K. van Breugel, "3D lattice fracture model: theory and computer implementation," Key Engineering Materials, vol. 452-453, pp. 69-72, 2010.

[26] C. Gu, Chloride Transport Property and Service Life Prediction of UHPFRCC under Flexural Load, Ph.D. thesis, Southeast Universtiy, Nanjing, China, 2016. 


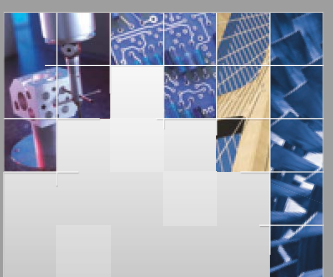

\section{Enfincering}
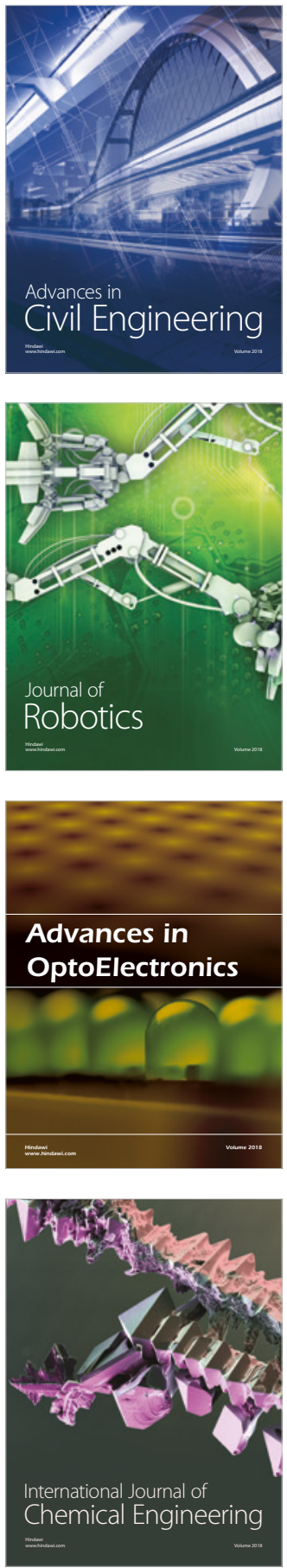

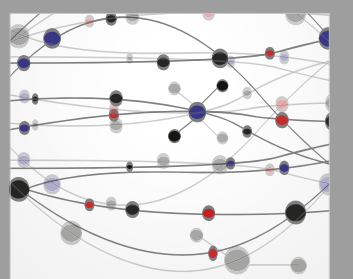

\section{Rotating \\ Machinery}

The Scientific World Journal

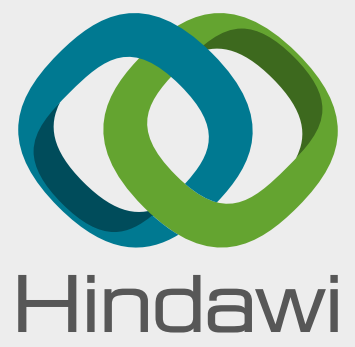

Submit your manuscripts at

www.hindawi.com
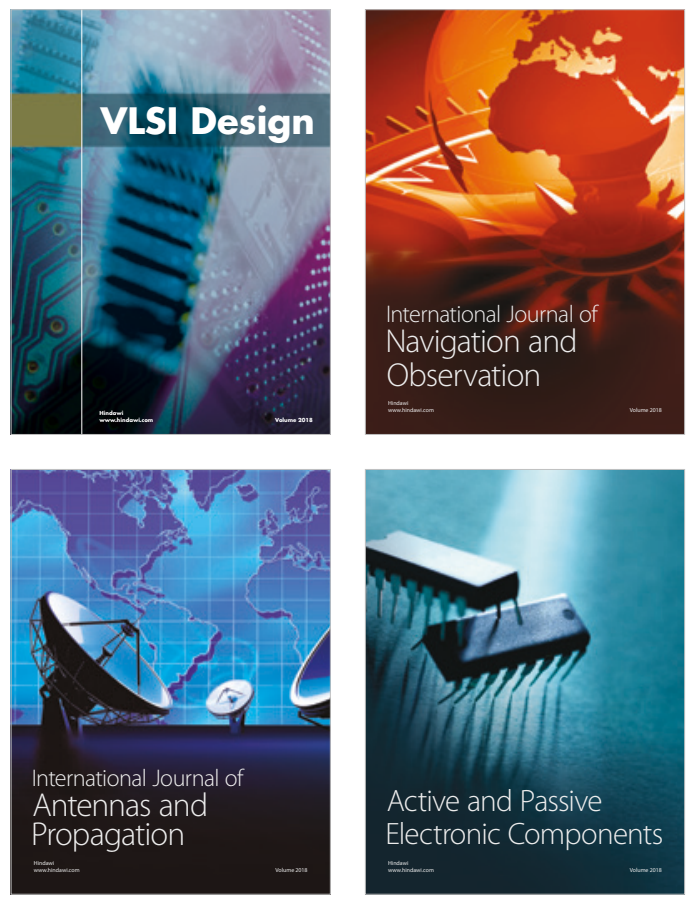
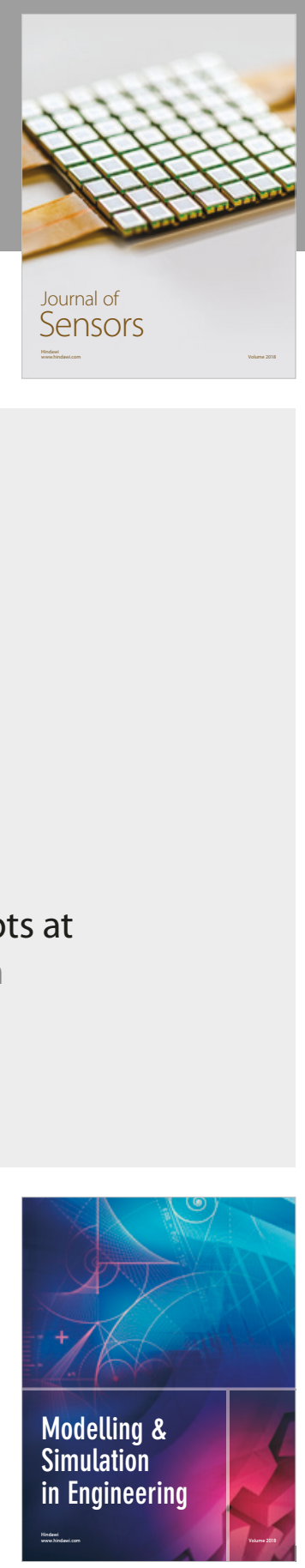

\section{Advances \\ Multimedia}
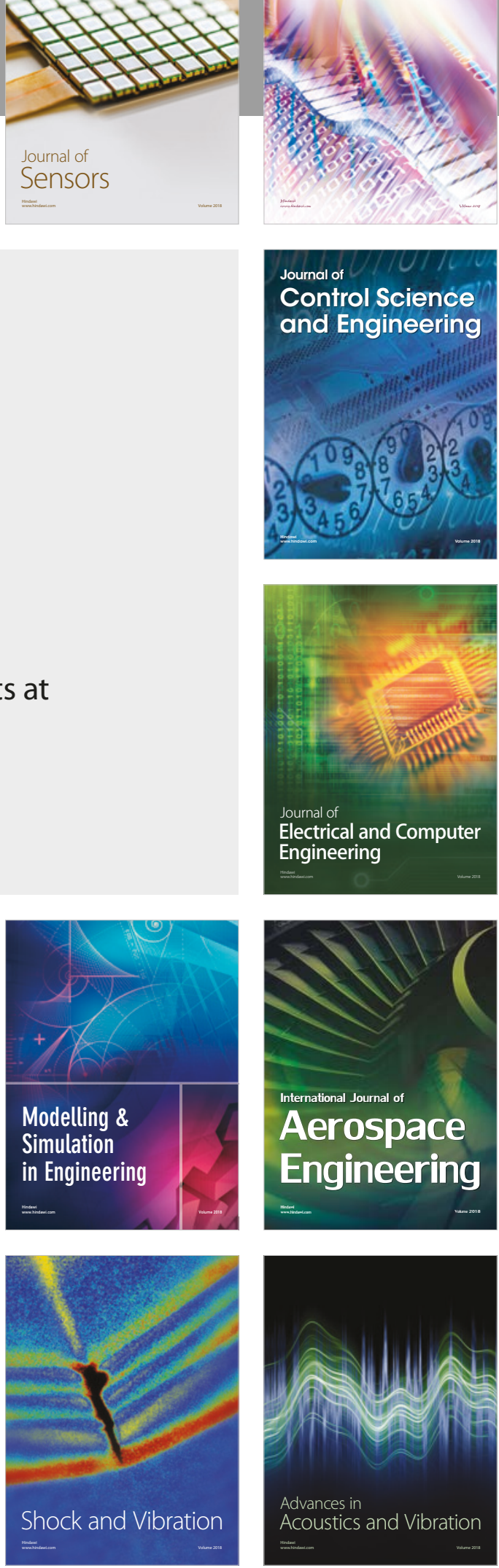